\title{
Biofilm Assays on Fibrinogen-coated Silicone Catheters and 96-well Polystyrene Plates
}

Cristina Colomer-Winter ${ }^{1}$, José A. Lemos ${ }^{1}$ and Ana L. Flores-Mireles ${ }^{2, *}$

\author{
${ }^{1}$ Department of Oral Biology, University of Florida College of Dentistry, Gainesville, FL, USA; \\ ${ }^{2}$ Department of Biological Sciences, University of Notre Dame, Notre Dame, IN, USA \\ *For correspondence: afloresm@nd.edu
}

\begin{abstract}
[Abstract] Biofilm formation is a well-known bacterial strategy that protects cells from hostile environments. During infection, bacteria found in a biofilm community are less sensitive to antibiotics and to the immune response, often allowing them to colonize and persist in the host niche. Not surprisingly, biofilm formation on medical devices, such as urinary catheters, is a major problem in hospital settings. To be able to eliminate such biofilms, it is important to understand the key bacterial factors that contribute to their formation. A common practice in the lab setting is to study biofilms grown in laboratory media. However, these media do not fully reflect the host environment conditions, potentially masking relevant biological determinants. This is the case during urinary catheterization, where a key element for Enterococcus faecalis and Staphylococcus aureus colonization and biofilm formation is the release of fibrinogen $(\mathrm{Fg})$ into the bladder and its deposition on the urinary catheter. To recapitulate bladder conditions during catheter-associated urinary tract infection (CAUTI), we have developed a fibrinogen-coated catheter and 96-well plate biofilm assay in urine. Notably, enterococcal biofilm factors identified in these in vitro assays proved to be important for biofilm formation in vivo in a mouse model of CAUTI. Thus, the method described herein can be used to uncover biofilm-promoting factors that are uniquely relevant in the host environment, and that can be exploited to develop new antibacterial therapies.
\end{abstract}

Keywords: Biofilm, Urine, Infection, Enterococcus faecalis, Fibrinogen, CAUTI, Catheter

[Background] Enterococcus faecalis is a leading cause of nosocomial infections, most notably infective endocarditis (IE) and catheter-associated urinary tract infections (CAUTI) (Arias et al., 2012; Chirouze et al., 2013; Flores-Mireles et al., 2015). Since these diseases are mainly biofilm-associated, a better understanding of how E. faecalis forms biofilms within the host can enable us to develop novel antibacterial therapies (Dunny et al., 2014).

The most common method to evaluate bacterial biofilm formation is the microplate biofilm assay, where bacteria are typically grown in microplate wells filled with laboratory media prior to analysis (Azeredo et al., 2017). However, there is increasing evidence that assays performed in laboratory growth media do not fully recapitulate conditions found within the host, and potentially overlook important bacterial factors required during infection (Nallapareddy and Murray, 2008; Guiton et al., 2013; FloresMireles et al., 2014; Colomer-Winter et al., 2017 and 2018; Xu et al., 2017). This is exemplified by studies investigating how $E$. faecalis forms biofilms on urinary catheters, a crucial step during persistent CAUTI (Nielsen et al., 2012; Guiton et al., 2013; Flores-Mireles et al., 2014, 2016a and 2016b). Early 
studies using animal models showed that E. faecalis forms robust biofilms on indwelling urinary catheters, and it was hypothesized that bacterial attachment occurred, at least in part, via Ebp, the endocarditis-and-biofilm-associated pilus (Nielsen et al., 2012). This hypothesis was substantiated by the finding that ebp deletion mutants were deficient in biofilm formation in vitro (in tryptic soy broth supplemented with $0.25 \%$ glucose [TSBG]) and in vivo, and were highly attenuated in animal models (Singh et al., 2007; Nallapareddy et al., 2011; Nielsen et al., 2012; Guiton et al., 2013; Sillanpaa et al., 2013; Flores-Mireles et al., 2014). However, the compelling body of work showing that Ebp-mediated biofilm formation is important during CAUTI contrasted with the observation that $E$. faecalis did not form biofilms in urine ex vivo (Flores-Mireles et al., 2014). This posed a significant paradox since urine is the environment that bacteria encounter during infection in the urinary tract. The paradox was resolved by the key finding that Ebp binds to fibrinogen (Nallapareddy et al., 2011) and that the host releases fibrinogen into the bladder as a result of catheter-associated inflammation (Flores-Mireles et al., 2014). Indeed, addition of fibrinogen to urine enhanced enterococcal biofilm formation ex vivo and enabled the discovery that $E$. faecalis cells attach to urinary catheters primarily via Ebp-fibrinogen interactions (Flores-Mireles et al., 2014). While this method successfully $d$ the results found in vivo, it ultimately confirmed the critical role of fibrinogen to enterococcal pathogenesis and led to the development of a vaccine therapy (Flores-Mireles et al., 2014, 2016a and 2016b). Similarly, the assay was later used to probe the importance of recapitulatemanganese uptake to enterococcal biofilm formation in urine (Colomer-Winter et al., 2018).

The method described (Figure 1) herein highlights the importance of developing assays that closely mimic the host environment to be able to study bacterial processes that are critical during infection. This concept is not restricted to the urinary tract or to E. faecalis, as it could be generally applied to studies of bacterial pathophysiology within the vertebrate host, like for example the oral cavity or the cardiovascular system.

\section{Materials and Reagents}

A. Bacterial growth and biofilm assay

1. $500 \mathrm{ml}$ Corning disposable sterile bottle-top filters with $0.22 \mu \mathrm{m}$ Membrane (Fisher Scientific, catalog number: 09-761-112)

2. $500 \mathrm{ml}$ Reusable Glass Media Bottles with Cap (Fisher Scientific, catalog number: FB800500)

3. $100 \times 15 \mathrm{~mm}$ Petri Dish (Fisher Scientific, catalog number: S43570)

4. $1 \mu l$ inoculating loops (DB Difco, catalog number: BD 220215)

5. $15 \mathrm{ml}$ Conical tube, for growing microaerophilic bacteria (Fisher Scientific, catalog number: 50153-5104)

6. Disposable Round-Bottom rimless glass tubes (Fisher Scientific, catalog number: 14-962-15A) and cap (Fisher Scientific, catalog number: 14-957-91)

7. Cuvettes, Standard: Polystyrene (Fisher Scientific, catalog number: 14-955-127)

8. $1.5 \mathrm{ml}$ microcentrifuge tubes (Fisher Scientific, catalog number: 02-682-002) 
9. Pipette tips

10. pH strips (EMD Millipore, catalog number: 1.09542.0001)

11. Catheter-Nalgene 50 silicone tubing (Nalgene Brand Products, catalog number: 80600030)

12. 96-well polystyrene plates (Grenier Bio-One CellSTAR, catalog number: 655180)

13. 96-well Microtitration plates (Corning, catalog number: 3788)

14. Axygen Scientific microplate presterilized sealing tape (Fisher Scientific, catalog number: 14222-044)

15. Bacterial species: Enterococcus faecalis OG1RF (ATCC 47077)

16. Double deionized water

17. 1x Phosphate sodium saline (Sigma-Aldrich, catalog number: P3813)

18. $0.1 \mathrm{~N}$ Hydrochloric acid solution ( $\mathrm{HCl})$ (Sigma-Aldrich, catalog number: 2104)

19. $0.1 \mathrm{~N}$ Sodium hydroxide ( $\mathrm{NaOH})$ (Sigma-Aldrich, catalog number: $\mathrm{SX0607 \textrm {C } )}$

20. Bovine serum albumin (Sigma-Aldrich, catalog number: A7906)

21. Agar, Bacteriological Grade (BD Difco, catalog number: B281230)

22. Human fibrinogen free from plasminogen and von Willebrand factor $(13-14 \mathrm{mg} / \mathrm{ml}$-concentration varies with each batch)(Enzyme Research Laboratory, catalog number: FIB 3)

23. Brain Heart Infusion broth (BHI) (BD Company, catalog number: B237500) or any other media for the requirements of your bacterial species

24. Pooled human urine (collected from at least three healthy female donors [Internal Review Board approval needed] or fresh urine commercially available).

Note: Urine should be fresh and stored under refrigeration for no longer than 3 days.

25. BHI liquid media (see Recipes)

26. BHI-agar plates (see Recipes)

27. Urine (see Recipes)

B. Assessment of biofilm formation on catheters

1. 12-well polystyrene microplate (Fisher Scientific, catalog number: 08-772-50)

2. Aluminum foil

3. $10 \%$ Neutral Buffered Formalin (Fisher Scientific, catalog number: 22-046-361)

4. $20 \%$ Sodium azide solution (Sigma-Aldrich, catalog number: S-2002)

5. Tween-20 (Sigma-Aldrich, catalog number: P1379)

6. Methyl $\alpha$-d-mannopyronoside (Sigma-Aldrich, catalog number: M6882)

7. Rabbit anti-Enterococcus antibody (Abcam, catalog number: ab68540) or any other antiEnterococcus antibody commercially available

8. IRDye 680LT goat anti-rabbit (LI-COR Biosciences, catalog number: 926-68021)

9. Immunostaining Solutions (see Recipes)
a. Blocking Solution
b. Wash Solution
c. Dilution Buffer 

d. Primary antibody solution
e. Secondary antibody solution

C. Assessment of Biofilm on microplate

1. Paper towel

2. Reagent reservoir (Fisher Scientific, catalog number: 14-387-065)

3. Crystal violet (Sigma-Aldrich, catalog number: C0775)

4. Acetic acid (Sigma-Aldrich, catalog number: A6283)

5. Solutions (see Recipes)
a. $0.5 \%$ Crystal violet solution
b. $33 \%$ of Acetic Acid

\section{Equipment}

1. Forceps

2. Heraeus Multifuge X3R Refrigerated Centrifuge (VWR, catalog number: 75004516) or any refrigerated centrifuge with similar features

3. Spectra Max ABS Plus Spectrophotometer (Molecular Devices, catalog number: ABS PLUS) or any spectrophotometer with similar features

4. Branson Ultrasonics ${ }^{\mathrm{TM}}$ Bransonic $^{\mathrm{TM}} \mathrm{CPX}$-sonicator (waterbath sonicator) (Fisher Scientific, catalog number: 15-337-419) or any waterbath sonicator with similar features

5. Odyssey CLx imaging system (LI-COR, catalog number: 9140-01)

6. Test tube racks (Fisher Scientific, catalog number: 14-809-62) or any standard test tube racks

7. VWR Microbiological Incubator (VWR, catalog number: 51030017) or any standard microbiological incubator

8. Biological Safety Cabinet with UV light (Thermo Fisher, catalog number: 1395) or any standard equipment with similar features

9. Vortexer (Fisher brand, catalog number: $02-215-418$ ) or any standard vortex

10. Autoclave (Getinge, catalog number: 633LS) or any standard autoclave

\section{$\underline{\text { Software }}$}

1. CLX image studio (LI-COR, catalog number: 9140-510)

2. GraphPad Prism (GraphPad Software LLC)

\section{Procedure}

The individual steps of this protocol are summarized in Figure 1. 


\begin{tabular}{|c|c|c|c|}
\hline \multirow[b]{2}{*}{ Day 1} & \multicolumn{3}{|c|}{ Protocol } \\
\hline & $\begin{array}{l}\text { Streak } E \text {. faecalis } \\
\text { in } \mathrm{BHI} \text { plates }\end{array}$ & $\begin{array}{l}\text { Prepare catheter pieces } \\
\text { and UV-sterilize them }\end{array}$ & Solution preparation \\
\hline Day 2 & $\begin{array}{l}\text { Pick a colony and } \\
\text { inoculate } 10 \mathrm{ml} \text { of } \\
\mathrm{BHI} \text { media }\end{array}$ & $\begin{array}{l}\text { Coat catheter silicone } \\
\text { pieces with fibrinogen }\end{array}$ & $\begin{array}{l}\text { Coat microplate } \\
\text { with fibrinogen }\end{array}$ \\
\hline Day 3 & \multicolumn{3}{|c|}{ Set biofilm formation experiment } \\
\hline Day 4 & \multicolumn{3}{|c|}{ Assessment of biofilm formation and data analysis } \\
\hline
\end{tabular}

Figure 1. Protocol layout

A. Bacterial growth

1. Streak the bacterial species on a BHI agar plate using a sterile inoculation loop.

2. Incubate bacteria overnight at $37^{\circ} \mathrm{C}$.

3. Add $10 \mathrm{ml}$ of $\mathrm{BHI}$ media into a $15 \mathrm{ml}$ conical tube.

4. Using a sterile inoculation loop, pick a single $E$. faecalis colony to inoculate the media.

5. Incubate the bacterial culture for $18 \mathrm{~h}$ at $37^{\circ} \mathrm{C}$ under static conditions (target $\mathrm{OD}_{600}=1.0$ ).

B. Catheter and microplate preparation

\section{Catheter}

1. Cut the silicone tubing in $1 \mathrm{~cm}$ pieces.

2. Cut in half the $1 \mathrm{~cm}$ pieces (Figure 2).

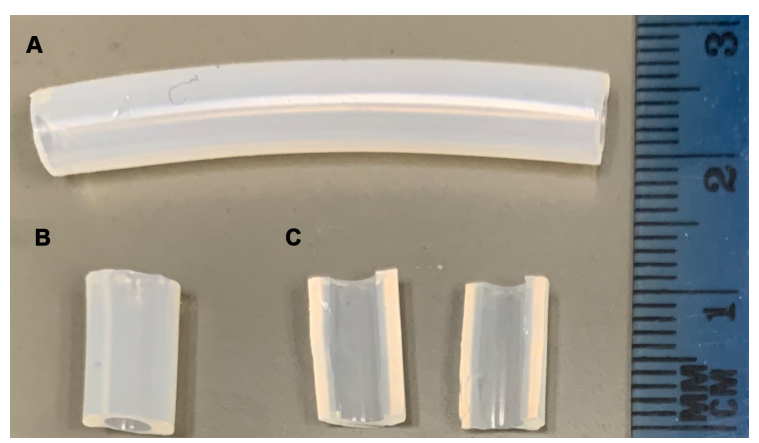

Figure 2. Preparation of $1 \mathrm{~cm}$ silicone pieces. A. Silicone tubing. B. $1 \mathrm{~cm}$ silicone pieces. C. $1 \mathrm{~cm}$ pieces in half.

3. Put the resulting pieces in an open Petri dish. 
4. UV-sterilize the pieces overnight (Biological Safety Cabinet standard UV settings)

5. Use sterile forceps to transfer each silicone piece into sterile $5 \mathrm{ml}$ glass test tube and cap it. Note: Fibrinogen is a sticky protein. Therefore use of a glass tube will reduce binding of fibrinogen to the tube walls.

6. Thaw the fibrinogen stock solution at $37^{\circ} \mathrm{C}$, and bring the $1 \times$ PBS solution to $37^{\circ} \mathrm{C}$. Fibrinogen is soluble at body temperature; therefore, keep it at $37^{\circ} \mathrm{C}$ until you add it to the silicone pieces.

7. Prepare a working solution of $100 \mu \mathrm{g} / \mathrm{ml}$ of fibrinogen in $1 \times$ PBS.

8. Add $1 \mathrm{ml}$ of the fibrinogen solution to the test tube containing the silicone piece.

9. Incubate the silicone pieces at $4{ }^{\circ} \mathrm{C}$ overnight under static conditions to allow fibrinogen to coat the catheter.

\section{Microplate}

10. Dispense $100 \mu \mathrm{l}$ of the $100 \mu \mathrm{g} / \mathrm{ml}$ fibrinogen solution (Step B7) into each well of the 96 -well polystyrene plates (Grenier Bio-One CellSTAR).

11. Seal the plate with a sterile plate sealing tape.

12. Incubate the microplate at $4{ }^{\circ} \mathrm{C}$ overnight to allow fibrinogen to coat the bottom of the well.

C. Culture preparation

1. Centrifuge the overnight culture (Step A5) for $10 \mathrm{~min}$ at 7,000 rpm $(7,505 \times \mathrm{g})$.

2. Remove supernatant.

3. Resuspend the bacterial pellet with $10 \mathrm{ml}$ of $1 \times$ PBS solution. Then centrifuge again for $10 \mathrm{~min}$ at 7,000 rpm $(7,505 \times \mathrm{g})$. Wash the bacterial cells by resuspending the bacterial pellet with 10 $\mathrm{ml}$ of $1 \times$ PBS solution. Repeat this step 3 times.

4. Dilute $1 \mathrm{ml}$ of bacterial solution into $9 \mathrm{ml}$ of $1 \times$ PBS solution (dilution 1:10). This step is necessary to ensure the accuracy of the measurement.

5. Take $1 \mathrm{ml}$ of the diluted solution and put it into a cuvette.

6. Measure optical density $\left(\mathrm{OD}_{600}\right)$ by using the spectrophotometer.

Note: Multiply the $O D_{600}$ value by 10 (dilution factor) to obtain the final optical density of the culture.

7. Dilute the culture to a final $\mathrm{OD}_{600}$ of 1.0 .

8. Supplement fresh filter-sterilized urine (see Recipe 2) with $20 \mathrm{mg} / \mathrm{ml}$ of BSA.

9. Filter sterilize the supplemented urine using bottle top filter.

10. Inoculate 1:100 of normalized culture (Step C7) into the filter-sterilized urine supplemented with BSA.

D. Catheter Fg-dependent biofilm setup

1. After overnight incubation at $4{ }^{\circ} \mathrm{C}$, remove the test tubes containing the Fg-coated silicone pieces (Step B9).

2. Aspirate the fibrinogen solution gently using a $1,000 \mu$ l pipette. 
3. Add $1 \mathrm{ml}$ of the bacteria-containing urine (Step C10). As negative control, incubate three Fgcoated pieces with only BSA-supplemented urine (no bacteria).

4. Incubate the tubes under static conditions at $37^{\circ} \mathrm{C}$ for $24 \mathrm{~h}$ (or as needed).

E. 96-well plate Fg-dependent biofilm set up

1. After overnight incubation at $4{ }^{\circ} \mathrm{C}$, remove the Fg-coated plates (Step B12).

2. Peel off the plate sealing tape.

3. Aspirate the fibrinogen solution gently using a pipette.

4. Add $200 \mu \mathrm{l}$ of the bacteria-containing urine (Step C10). As negative control, incubate $8 \mathrm{Fg}$ coated wells (one column of the microplate) with only urine (no bacteria).

5. Cover the plate with a sterile lid.

6. Incubate the microplate tubes under static conditions at $37^{\circ} \mathrm{C}$ for $24 \mathrm{~h}$ (or as needed).

F. Assessment of the catheter biofilm

1. Aspirate the bacterial culture from the tube using a 1,000 $\mu \mathrm{l}$ pipette.

2. Remove the unbound bacteria by pipetting vigorously using $1 \mathrm{ml}$ of $1 \times \mathrm{PBS}$ at room temperature. Repeat this step 3 times.

\section{Assessment of biofilm formation by colony forming units}

3. Transfer the silicone piece with sterile forceps (from Step F2) into a $15 \mathrm{ml}$ conical tube.

4. Add $1 \mathrm{ml}$ of $1 \times$ PBS.

5. To detach the bacterial biofilm from the catheter, vortex for $30 \mathrm{~s}$ (maximum vortex's speed) at room temperature.

6. Put conical tube into the Branson ultrasonic bath for $5 \mathrm{~min}$ at room temperature $(40 \mathrm{kHz}$ frequency), and vortex for another $30 \mathrm{~s}$.

7. Take a $200 \mu \mathrm{l}$ sample and serially dilute it with PBS (1:10).

8. Plate dilutions on $\mathrm{BHI}$ agar plates.

9. Incubate the plates at $37^{\circ} \mathrm{C}$ overnight.

10. Quantify colony forming units (Figure 3 ).

\section{Assessment of biofilm formation by immunostaining}

3. After washing the silicone pieces (Step F2), transfer them to a 12-well plate.

4. Fix the silicone pieces by adding $5 \mathrm{ml}$ of $10 \%$ neutralizing formalin solution for $20 \mathrm{~min}$.

5. Remove the formalin.

6. Wash the pieces by adding $5 \mathrm{ml}$ of PBS (repeat 3 times). All washes in this protocol are done under static conditions at room temperature unless otherwise noted.

7. Block the pieces by adding $5 \mathrm{ml}$ blocking solution for $1 \mathrm{~h}$ at room temperature (or at $4{ }^{\circ} \mathrm{C}$ overnight).

8. Wash the pieces with $5 \mathrm{ml}$ wash solution. Repeat this step 3 times. 
9. Add $5 \mathrm{ml}$ of the primary antibody solution.

10. Incubate for $2 \mathrm{~h}$ at room temperature under static conditions.

11. Wash the pieces with $5 \mathrm{ml}$ wash solution. Repeat this step 3 times.

12. Add $5 \mathrm{ml}$ of the secondary antibody solution. Cover the plate with aluminum foil (secondary antibody is sensitive to light).

13. Incubate for $1 \mathrm{~h}$ at room temperature under static conditions

14. Wash the pieces with $5 \mathrm{ml}$ wash solution. Repeat this step 3 times.

15. Transfer the pieces into a new 12-well plate.

16. Let them dry overnight.

17. Visualize the biofilm using the Odyssey imager (detection at $700 \mathrm{~nm}$ near-infrared region) (Figure 4).

\section{Colorimetric assessment of biofilm formation by crystal violet}

3. After washing the silicone pieces (Step F2), transfer them to a 12-well plate.

4. Let pieces air dry.

5. Add $5 \mathrm{ml}$ of $0.5 \%$ of crystal violet solution.

6. Stain for 10 min under static conditions at room temperature.

7. Wash the pieces with distilled water (repeat this step 3 times).

8. Add $1 \mathrm{ml}$ of $33 \%$ acetic acid to solubilize the crystal violet staining.

9. Incubate for $15 \mathrm{~min}$ at room temperature under static conditions.

10. Transfer $200 \mu \mathrm{l}$ of the solubilized crystal violet into a new microplate.

11. Quantify absorbance at $595 \mathrm{~nm}$ using a plate reader. As a blank, use the $33 \%$ acetic acid in water. Serial dilution may be required to fall into the linear range of the plate reader.

G. Assessment of the microplate biofilm

1. After incubation (Step E6), remove the culture by inverting the plate.

2. Wash the unbound cells by submerging the plate in a small container full of water. Shake the plate gently and shake out the water. Repeat this step 3 times.

3. Dry the plate by tapping gently on a paper towel to remove residual liquid.

4. Let the plate air dry.

5. Add $200 \mu \mathrm{l}$ of $0.5 \%$ of crystal violet solution.

6. Stain for 10 min under static conditions at room temperature.

7. Rinse by submerging the plate into the container full of water. Once submerged, shake the plate vigorously, dump the liquid, and tap the plate on a paper towel to remove the residual liquid. Repeat this step 3 times.

8. Add $200 \mu \mathrm{l}$ of $33 \%$ acetic acid to solubilize the crystal violet staining.

9. Incubate for $15 \mathrm{~min}$ at room temperature under static conditions.

10. Transfer $200 \mu \mathrm{l}$ of the solubilized crystal violet into a new microplate.

11. Quantify absorbance at $595 \mathrm{~nm}$ using a plate reader. As a blank use the $33 \%$ acetic acid in 
water. Serial dilution may be required to fall into the linear range of the plate reader.

\section{Data analysis}

A. Analysis of biofilm-associated CFU

1. $\log _{10}$ transform final bacterial counts recovered from each catheter $(n \geq 3)$ (Figure 3$)$.

2. Plot data on a linear scale and include the arithmetic mean.

3. Depending on the amount of groups you want to compare, analyze the $\log _{10}$-transformed data with either a two-tailed Mann-Whitney $U$ test or a one-way ANOVA followed by an appropriate post-test comparison.

Note: $\log _{10}$ transformation is optional. An alternative way to plot and analyze the data would be to plot untransformed data on a log scale with the geometric mean and the geometric standard deviation.

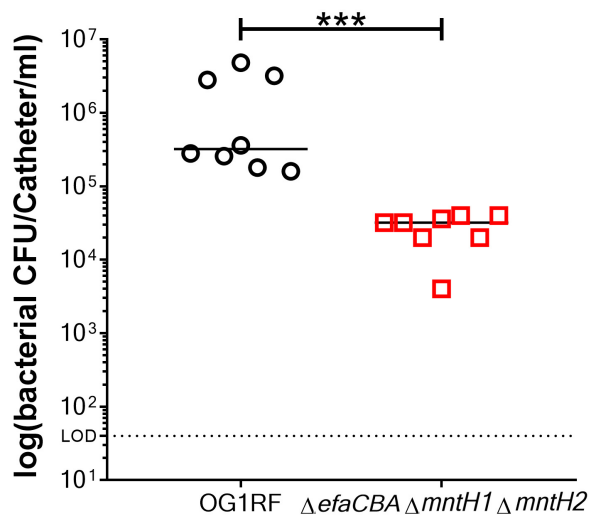

Figure 3. Representative data of biofilm measured by colony forming units (CFU). Comparison of biofilm formation between $E$. faecalis OG1RF (wild-type strain) and a manganese uptake system triple mutant strain ( $\Delta$ efa $\Delta m n t H 1 \Delta m n t H 2)$, which is a biofilm deficient mutant. Two-tailed Mann-Whitney $U$ tests were performed to determine significance between two groups ( $\left.{ }^{\star \star \star} P<0.0002\right)$.

B. Analysis of biofilm formation assessed by immunostaining or crystal violet

1. Plot the relative fluorescence to the negative control (Figure 4) or absorbance (relative to the negative control) for each group $(n \geq 3)$ on a linear scale and include the arithmetic mean and the standard deviation.

2. Analyze the data with a Mann-Whitney $U$ test. Notes:

a. The biofilm formation assays on catheters often do not follow a normal distribution as determined by the D'Agostino-Pearson test. Thus, a nonparametric analysis such as the MannWhitney $U$ test is more appropriate than the parametric ANOVA test. 
b. Outliers can be identified using the ROUT method ( $Q=1 \%$ recommended) and can be removed from the final analysis if confirmed.
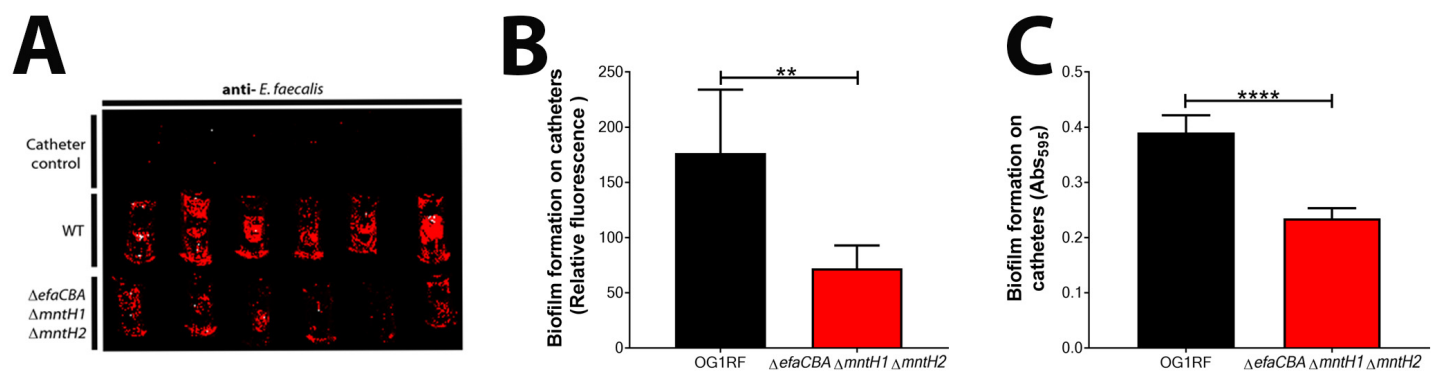

Figure 4. Representative images and data of biofilm analyzed by immunostaining and crystal violet. A. Visualization of biofilm formation on catheter pieces by $E$. faecalis OG1RF and a manganese uptake system triple mutant strain ( $\triangle e f a \Delta m n t H 1 \Delta m n t H 2)$. Catheter controls are those Fg-coated catheters that were incubated with only urine (no bacteria). B. Immunostaining analysis of biofilm formation between OG1RF WT and deficient mutant by plotting fluorescence relative to catheter controls. C. CV staining to quantify and compare biofilm formation between OG1RF WT and deficient mutant by plotting absorbance relative to catheter controls. Two-tailed Mann-Whitney $\mathrm{U}$ tests were performed to determine significance between two groups ( $\left.{ }^{\star \star \star} P<0.0002\right)$.

\section{Recipes}

1. Media

a. BHI liquid media

Add $37 \mathrm{~g}$ of $\mathrm{BHI}$ broth powder into $1 \mathrm{~L}$ of distilled water

Mix until solution is clear

Autoclave for $20 \mathrm{~min}$

Let media cool down to room temperature prior to use

b. BHI-agar plates

Add $37 \mathrm{~g}$ of $\mathrm{BHI}$ broth powder and $15 \mathrm{~g}$ of agar into $1 \mathrm{~L}$ of distilled water

Mix until solution is clear

Autoclave for $20 \mathrm{~min}$

Let media cool down to a temperature of $45^{\circ} \mathrm{C}$

Add antibiotics if needed and mix

Keep media warm and pour $25 \mathrm{ml}$ of media into Petri dishes

2. Urine

a. Pool the urine from at least three healthy female donors (or get commercially available pooled urine). Use the same urine batch for consistency during the study

b. Centrifuge pooled urine for $5 \mathrm{~min}$ at $7,000 \mathrm{rpm}(7,505 \times \mathrm{g})$ to remove precipitates 
c. Measure $\mathrm{pH}$ using $\mathrm{pH}$ strips and adjust to 6.5 using $\mathrm{HCl}$ solution or $\mathrm{NaOH}$ solutions as needed

d. Filter sterilize the pooled urine using bottle top filters. Preferentially use fresh urine every time. In case, it is not used right away, store urine at $4{ }^{\circ} \mathrm{C}$ for no longer than 3 days. Repeat centrifugation for $5 \mathrm{~min}$ at $7,000 \mathrm{rpm}(7,505 \times \mathrm{g})$ if formation of precipitates is observed

3. Solutions

a. Blocking Solution

1x PBS with $1.5 \%$ BSA and $0.1 \%$ Sodium Azide. Keep solution at $4{ }^{\circ} \mathrm{C}$

b. Wash Solution

1x PBS with $0.05 \%$ Tween-20. Keep solution at room temperature

c. Dilution Buffer

1x PBS with $0.05 \%$ Tween-20, 0.1\% BSA, and 0.5\% methyl $\alpha$-d-mannopyronoside. Keep solution at $4{ }^{\circ} \mathrm{C}$

d. Primary antibody solution

Add 1:500 of rabbit anti-Streptococcus group $D$ antigen antisera into dilution buffer. Prepare fresh every time

e. Secondary antibody solution

Add 1:10,000 of goat anti-rabbit IRDye 680LT into dilution buffer. Prepare fresh every time

f. $\quad 0.5 \%$ Crystal violet solution

Add $0.5 \mathrm{mg}$ into $100 \mathrm{ml}$ of distilled water. Filter sterilize the solution. Keep solution at room temperature

g. $33 \%$ of Acetic Acid

Add $330 \mathrm{ml}$ of Acetic acid into $670 \mathrm{ml}$ of distilled water. Keep solution at room temperature

\section{Acknowledgments}

C.C.W. was supported by American Heart Association GSA Predoctoral Fellowship 16PRE29860000, J.A.L. was supported by National Institute of Allergy and Infectious Disease Al135158, A.L.F.M. was supported by startup funds from the University of Notre Dame.

Special acknowledgment to previous studies done by Nallapareddy et al. (2011) and FloresMireles et al. (2014).

\section{Competing interests}

The authors declare no competing financial interests. 


\section{References}

1 Arias, C. A. and Murray, B. E. (2012). The rise of the Enterococcus: beyond vancomycin resistance. Nat Rev Microbiol 10(4): 266-278.

2 Azeredo, J., Azevedo, N. F., Briandet, R., Cerca, N., Coenye, T., Costa, A. R., Desvaux, M., Di Bonaventura, G., Hebraud, M., Jaglic, Z., Kacaniova, M., Knochel, S., Lourenco, A., Mergulhao, F., Meyer, R. L., Nychas, G., Simoes, M., Tresse, O. and Sternberg, C. (2017). Critical review on biofilm methods. Crit Rev Microbiol 43(3): 313-351.

3 Chirouze, C., Athan, E., Alla, F., Chu, V. H., Ralph Corey, G., Selton-Suty, C., Erpelding, M. L., Miro, J. M., Olaison, L., Hoen, B. and International Collaboration on Endocarditis Study, G. (2013). Enterococcal endocarditis in the beginning of the $21^{\text {st }}$ century: analysis from the International Collaboration on Endocarditis-Prospective Cohort Study. Clin Microbiol Infect 19(12): 1140-1147.

4 Colomer-Winter, C., Flores-Mireles, A. L., Baker, S. P., Frank, K. L., Lynch, A. J. L., Hultgren, S. J., Kitten, T. and Lemos, J. A. (2018). Manganese acquisition is essential for virulence of Enterococcus faecalis. PLoS Pathog 14(9): e1007102.

5 Colomer-Winter, C., Gaca, A. O. and Lemos, J. A. (2017). Association of metal homeostasis and (p)ppGpp regulation in the pathophysiology of Enterococcus faecalis. Infect Immun 85(7).

6 Dunny, G. M., Hancock, L. E. and Shankar, N. (2014). Enterococcal biofilm structure and role in colonization and disease. Gilmore, M. S., Clewell, D. B., Ike, Y. and Shankar, N. (Eds.). In: Enterococci: from commensals to leading causes of drug resistant infection. Boston.

7 Flores-Mireles, A. L., Pinkner, J. S., Caparon, M. G. and Hultgren, S. J. (2014). EbpA vaccine antibodies block binding of Enterococcus faecalis to fibrinogen to prevent catheter-associated bladder infection in mice. Sci Transl Med 6(254): 254ra127.

8 Flores-Mireles, A. L., Walker, J. N., Caparon, M. and Hultgren, S. J. (2015). Urinary tract infections: epidemiology, mechanisms of infection and treatment options. Nat Rev Microbiol 13(5): 269-284.

9 Flores-Mireles, A. L., Walker, J. N., Bauman, T. M., Potretzke, A. M., Schreiber, H. L. t., Park, A. M., Pinkner, J. S., Caparon, M. G., Hultgren, S. J. and Desai, A. (2016a). Fibrinogen release and deposition on urinary catheters placed during urological procedures. $J$ Urol 196(2): 416421.

10 Flores-Mireles, A. L., Walker, J. N., Potretzke, A., Schreiber, H. L. t., Pinkner, J. S., Bauman, T. M., Park, A. M., Desai, A., Hultgren, S. J. and Caparon, M. G. (2016b). Antibody-based therapy for enterococcal catheter-associated urinary tract infections. MBio 7(5): e01653-16.

11 Guiton, P. S., Hannan, T. J., Ford, B., Caparon, M. G. and Hultgren, S. J. (2013). Enterococcus faecalis overcomes foreign body-mediated inflammation to establish urinary tract infections. Infect Immun 81(1): 329-339. 
12 Nallapareddy, S. R. and Murray, B. E. (2008). Role played by serum, a biological cue, in the adherence of Enterococcus faecalis to extracellular matrix proteins, collagen, fibrinogen, and fibronectin. J Infect Dis 197(12): 1728-1736.

13 Nallapareddy, S. R., Singh, K. V., Sillanpaa, J., Zhao, M. and Murray, B. E. (2011). Relative contributions of Ebp Pili and the collagen adhesin ace to host extracellular matrix protein adherence and experimental urinary tract infection by Enterococcus faecalis OG1RF. Infect Immun 79(7): 2901-2910.

14 Nielsen, H. V., Guiton, P. S., Kline, K. A., Port, G. C., Pinkner, J. S., Neiers, F., Normark, S., Henriques-Normark, B., Caparon, M. G. and Hultgren, S. J. (2012). The metal ion-dependent adhesion site motif of the Enterococcus faecalis EbpA pilin mediates pilus function in catheterassociated urinary tract infection. MBio 3(4): e00177-00112.

15 Sillanpaa, J., Chang, C., Singh, K. V., Montealegre, M. C., Nallapareddy, S. R., Harvey, B. R., Ton-That, H. and Murray, B. E. (2013). Contribution of individual Ebp Pilus subunits of Enterococcus faecalis OG1RF to pilus biogenesis, biofilm formation and urinary tract infection. PLoS One 8(7): e68813.

16 Singh, K. V., Nallapareddy, S. R. and Murray, B. E. (2007). Importance of the ebp (endocarditisand biofilm-associated pilus) locus in the pathogenesis of Enterococcus faecalis ascending urinary tract infection. $J$ Infect Dis 195(11): 1671-1677.

17 Xu, W., Flores-Mireles, A. L., Cusumano, Z. T., Takagi, E., Hultgren, S. J. and Caparon, M. G. (2017). Host and bacterial proteases influence biofilm formation and virulence in a murine model of enterococcal catheter-associated urinary tract infection. NPJ Biofilms Microbiomes 3: 28. 